\title{
PATIENTS' KNOWLEDGE, ATTITUDES, AND PRACTICES ON UNCOMPLICATED MALARIA MANAGEMENT IN PLATEAU STATE, NORTH-CENTRAL NIGERIA
}

\author{
NANLOH S JIMAM ${ }^{1,2}$, NAHLAH E ISMAIL ${ }^{1 *}$ \\ ${ }^{1}$ Department of Clinical Pharmacy, Faculty of Pharmacy, MAHSA University, Selangor, Malaysia, ${ }^{2}$ Department of Clinical Pharmacy and \\ Pharmacy Practice, Faculty of Pharmaceutical Sciences, University of Jos, Jos, Nigeria. Email: nahlah@mahsa.edu.my
}

Received: 17 November 2018, Revised and Accepted: 13 January 2019

\section{ABSTRACT}

Objectives: This study aimed to assess patients' knowledge, attitudes, and practices (KAP) on uncomplicated malaria management in primary healthcare (PHC) facilities of Plateau state, Nigeria.

Methods: A validated self-reported scale known as patients' KAP instrument for uncomplicated malaria with Cronbach's alpha reliability of 0.74 was administered to 956 patients that consented to participate in the study across 24 PHC facilities in the state between May and July 2017. The collated data were analyzed using Microsoft Excel and IBM Statistical Package for the Social Sciences (SPSS ${ }^{\circledR}$ ) version 23 software.

Results: There were more female participants (53.5\%) compared to the males (46.5\%), and majority (33.4\%) within the age range of 28 and 37 years with $26.5 \%$ falling within the age range of $18-27$ years and children of $<18$ years of age constituted $13.8 \%$ of the study population. About $42.1 \%$ of the respondents were married, and many either had secondary (37.3\%) or primary (30.0\%) education as their highest qualifications. With overall mean ( \pm standard deviation [SD]) attitudes' score of $34.55( \pm 7.20)$, majority $(50.8 \%)$ were categorized as having average positive attitudes toward disease and its management, and many of them (55.2\%) also had good knowledge (mean $[ \pm$ SD] score $=4.59$ [ \pm 1.44$]$ ) and practices $(67.1 \%)$ (mean $[ \pm \mathrm{SD}]$ score $=14.98[ \pm 3.44]$ ) on the disease and its management.

Conclusion: The study indicated respondents' knowledge and practices on uncomplicated malaria as good, while their attitudes toward the disease and its management were average.

Keywords: Antimalarial drugs, Knowledge, Attitudes and practices, Patients, Primary health care, Uncomplicated malaria.

(c) 2019 The Authors. Published by Innovare Academic Sciences Pvt Ltd. This is an open access article under the CC BY license (http://creativecommons. org/licenses/by/4. 0/) DOI: http://dx.doi.org/10.22159/ajpcr.2019.v12i3.30459

\section{INTRODUCTION}

Malaria is a vector-borne disease caused by Plasmodium parasites and is common in tropical and subtropical climates [1]. It is one of the leading causes of morbidity and mortality in sub-Saharan Africa, with about $88 \%$ and $90 \%$ of the estimated global cases and deaths, respectively, occurring in the region $[1,2]$. Nigeria was responsible for about $25 \%$ of the African malaria burdens, with Plasmodium falciparium responsible for about $98 \%$ of the cases, and the disease accounted for about $60 \%$ outpatient visits to health facilities in the country in $2015[2,3]$. This has been linked to many factors including high prevalence of inappropriate use of antimalarial drugs and favorable climatic conditions of the areas which have been shown to encourage the survival and productivity of the vector mosquitoes [4-9].

Patients' inappropriate medications practices have been shown to be associated with many factors which could either be intentional or unintentional, complexity of a medication regimen (polypharmacy) and patient's memory, health-care professionals' practices, or even economic reasons among many factors [10-13]. Considering the established interrelationships between the human behavior-related characteristics such as knowledge, attitudes, and practices (KAP) and their influence on rational management of ailments [14-16], evaluation of these patients' behavior-related attributes as it relates to the management of uncomplicated malaria becomes necessary for intervention purposes, especially at the rural communities where majority of the populations are most affected by the disease $[6,12,14,17,18]$. The present study was mainly to assess patients' KAP toward uncomplicated malaria management in primary health-care (PHC) facilities in Plateau state, Nigeria.

\section{METHODS}

\section{Ethics approval}

The study was approved by the Joint Research Review and Ethics Committee, Research Management Centre (RMC), MAHSA University, Malaysia (Ref. number: RMC/EC01/2016; dated 25/11/2016). This was followed by subsequent permission granted by Plateau State Ministry of Health, Jos, Nigeria, and the directors of PHCs of the various selected Local Government Areas to use the PHC facilities.

\section{Study design and location}

A cross-sectional KAP method was used during the survey in Plateau state, located in north-central part of Nigeria with a landmark of $30,913 \mathrm{~km}^{2}$ and population of 5,178,712 according to 2006 national population census [19].

\section{Sampling methods and sample size estimation}

A multistage probability sampling techniques including stratified and simple random approaches were used in selecting 24 public PHC facilities across the state, and 50 patients receiving treatment for uncomplicated malaria during the study period were recruited from each of the selected PHC facilities, totaling 1200 calculated sample size for patients to participate in the study [20]. The sample size for the survey was estimated in accordance with the World Health Organization manual on how to investigate drug use in health facilities [20,21].

\section{Study instrument}

The instrument comprised four subsections. The sociodemographic characteristics subsection consisted of six items that inquired basic information on the respondents including gender, age, marital status, level of education, occupation, and monthly income. 
There were seven items designed presented as "yes," "no," or "not sure" to test respondents' knowledge on the etiology, transmission, sign, and symptoms, as well as the recommended drugs used in the management of uncomplicated malaria.

The attitudes subsection consisted of ten items presented on five-point Likert's scale to assess respondents' attitudes toward uncomplicated malaria disease and its' management. Finally, the practices subsection had four items which were also scored on five-point Likert's scale to understand respondents' general practices during medications treatment of the disease.

\section{Data collection}

Respondents who were $\geq 18$ years of age consented to participate in the study by filling patients' consent form before data collection. Those between the ages of 12 and $<18$ years who were in secondary school and could read and write also filled the self-administered instruments themselves after consent to participate in the study were granted by their guardians. For those $<12$ years old, their guardians/caregivers responded on their behalf since the disease was prevalent in the state and country at large. In all, $956(79.7 \%)$ of the target populations receiving treatment for uncomplicated malaria that was available during the survey in the selected PHC facilities participated in the study. A designed and validated patients' self-reported instrument known as patients' KAP instrument for uncomplicated malaria (PKAPIUM) with Cronbach's alpha reliability of 0.74 was administered to them to filled and returned for descriptive statistical analysis.

\section{Data analysis}

The generated data were manually sorted and entered into Microsoft Excel software based on coded format and saved under password protected files in a secured laptop. The variables were quantified and reported by descriptive statistics using IBM Statistical Package for the Social Sciences (SPSS ${ }^{\circledR}$ ) version 23 software.

Before calculation of the respondents' total scores to the items through descriptive statistics, all negatively stated items were coded in reverse directions so that higher scores could imply better knowledge, attitude, and practices. The knowledge categorization was based on their levels of correct responses to the seven items used for knowledge assessment which was assessed using three options of "yes," "not sure," or "no," and these were dichotomized into "yes" $=1$ and "no" or "not sure" $=0$ to ensure objectivity in the assessment of the respondents' knowledge on the disease and its' management. In all, there was a total of possible maximum correct score of 7. Patients who answered between 6 and 7, 4 and 5, and 1-3 items correctly had scores of between $6-7,4-5$, and 1-3 and were, respectively, categorized as having good, average, and poor knowledge [22,23].

The scoring system for the ten attitudes-related items for patients on the five-point Likert's scale was based on their levels of agreements to the statements, which were categorized into "strongly agree" $=5$ points, "agree" $=4$ points, "neutral" $=3$ points, "disagree" $=2$ points, and "strongly disagree" $=1$ point, and there was a total of possible maximum score of 50 for the patients with scores of 37-50, 25-36, and 1-24 categorized as good, average, and poor attitudes.

Four statements indicating uncomplicated malaria-related practices were used to assess the respondents' uncomplicated malaria treatment practices on five-points Likert's scale, which were scored as, 5=very often, $4=$ often, $3=$ =sometimes, 2 =rarely, 1 =never, without reversing the score for any of the items since all the statements were positively stated. There was a total possible maximum score of 20 , and patients who scored between 15 and 20 were categorized as performing good during their medication practices, while those with scores of 10-14, and scores of 1-9 were categorized as having average and poor practices.

\section{RESULTS}

\section{Sociodemographic characteristics of respondents}

Nine hundred and fifty-six (79.7\%) patients participated in the study, with the majority of females $(54.7 \%)$. About $33.6 \%$ of them fall within
Table 1: Patients' sociodemographics characteristics $(n=956)$

\begin{tabular}{ll}
\hline Variables & Total, $\mathbf{n}$ (\%) \\
\hline Gender & \\
$\quad$ Male & $433(45.3)$ \\
Female & $523(54.7)$ \\
Age (years old) & \\
$\quad<18$ & $142(14.9)$ \\
$18-27$ & $266(27.8)$ \\
$28-37$ & $321(33.6)$ \\
$38-47$ & $227(23.7)$ \\
$\geq 48$ & $142(14.9)$ \\
Marital status & \\
Never married & $343(35.9)$ \\
Married & $407(42.6)$ \\
Divorce/widowed & $206(21.5)$ \\
Education & \\
No formal education & $137(14.3)$ \\
Primary education & $268(28.0)$ \\
Secondary education & $358(37.5)$ \\
Higher education & $193(20.2)$ \\
Occupations & \\
Students & $287(30.0)$ \\
Employed & $335(35.1)$ \\
Farmer/business & $334(34.9)$ \\
Monthly income (naira) & \\
None & \\
$<18,000$ & $481(50.3)$ \\
18,000-40,000 & $165(17.3)$ \\
$>40,000$ & $200(20.9)$ \\
\hline & $110(11.5)$ \\
\hline
\end{tabular}

the age brackets of 28 and 37 years, followed by those in the age ranges of $18-27(27.8 \%)$ and children of $<18$ years old (14.9\%). Most of the respondents $(42.6 \%)$ were married. Many of them either had secondary $(37.5 \%)$ or primary $(28.0 \%)$ education as their highest qualifications, and many of them $(50.3 \%)$ were not on any forms of monthly income (Table 1 ).

\section{Respondents' knowledge}

The respondents' knowledge on uncomplicated malaria and its management is shown in Table 2 . About $89.0 \%$ of the patients knew that mosquitoes bite was the main means of malaria transmission, and $88.5 \%$ knew that children and pregnant women were at more risk of developing the disease. Similarly, $86.9 \%$ of them were able to recognize rise in body temperature and $84.2 \%$ recognized body weakness as correct symptoms for uncomplicated malaria.

Regarding their knowledge on antimalarial drugs, majority of them (53.2\%) knew that artemisinin-based combination drug was the recommended drug for uncomplicated malaria. However, many of them $(45.0 \%)$ were not sure of the true position of sulfad oxine-pyrimethamine in the management of the disease, with $32.5 \%$ admitting that it was the recommended drug for uncomplicated malaria, while $22.5 \%$ did not agree. Similarly, high percentage $(35.3 \%)$ of the participants disagreed that chloroquine was the recommended antimalarial drug, with almost the same percentage (34.6\%) agreeing with the notion (Table 2 ).

\section{Malaria-related knowledge category}

With overall mean ( \pm standard deviation [SD]) knowledge score of $4.59( \pm 1.44)$, majority of the respondents $(55.2 \%)$ scored between six and seven points and were categorized as having good knowledge of the disease and its management, followed by $27.5 \%$ of them who got between four and five points and were considered as having average knowledge, and $17.3 \%$ scored $<4$ were considered having poor knowledge on the disease and its management (Fig. 1).

\section{Respondents' attitude toward uncomplicated malaria}

All the ten items were negatively constructed such that respondent agreeing with it could be an indication of bad attitudes toward management practices, while their levels of disagreeing with the statements were measures of their good attitudes toward the practices. The percentage of respondents that disagreed with the individual items 
Table 2: Respondents' knowledge on the transmission and treatment of uncomplicated malaria (n=956)

\begin{tabular}{|c|c|c|c|}
\hline Knowledge statements & Yes, n (\%) & No, $n(\%)$ & Not sure, n (\%) \\
\hline \multicolumn{4}{|l|}{ Knowledge on transmission and symptoms } \\
\hline Malaria is transmitted by mosquitoes bite & $851(89.0)^{*}$ & $52(5.4)$ & $52(5.4)$ \\
\hline Children and pregnant women are at higher risk of developing malaria & $846(88.5)^{*}$ & $45(4.7)$ & $65(6.8)$ \\
\hline Rise in body temperature is a symptom of malaria & $831(86.9)^{*}$ & $47(4.9)$ & $78(8.2)$ \\
\hline Body weakness is a symptom of malaria & $805(84.2)^{*}$ & $61(6.4)$ & $90(9.4)$ \\
\hline \multicolumn{4}{|l|}{ Knowledge on antimalarial drugs } \\
\hline ACT is the recommended antimalarial drug for uncomplicated malaria in Nigeria & $509(53.2)^{*}$ & $109(11.4)$ & $338(35.4)$ \\
\hline Chloroquine is the recommended antimalarial drug for uncomplicated malaria in Nigeria & $331(34.6)$ & $337(35.3)^{*}$ & $288(30.1)$ \\
\hline
\end{tabular}

*Correct response. ACT: Artemisinin-based combination therapy

Table 3: Respondents' attitudes toward uncomplicated malaria and its management $(n=956)$

\begin{tabular}{|c|c|c|c|c|c|}
\hline Attitudinal statements & $\begin{array}{l}\text { Strongly } \\
\text { agree, n (\%) }\end{array}$ & $\begin{array}{l}\text { Agree, } \\
\text { n (\%) }\end{array}$ & $\begin{array}{l}\text { Neutral, } \\
\text { n (\%) }\end{array}$ & $\begin{array}{l}\text { Disagree, } \\
\text { n (\%) }\end{array}$ & $\begin{array}{l}\text { Strongly } \\
\text { disagree, n (\%) }\end{array}$ \\
\hline Most of the antimalarials drugs in circulation are fake & $126(13.2)$ & $187(19.6)$ & $253(26.4)$ & $323(33.8)$ & $67(7.0)$ \\
\hline $\begin{array}{l}\text { Herbal medicine is more effective in treating malaria than orthodox } \\
\text { drug }\end{array}$ & $37(3.9)$ & $106(11.1)$ & $74(7.7)$ & $550(57.5)$ & $189(19.8)$ \\
\hline I do not like taking ACTs because of its unwanted effects & $54(5.7)$ & $161(16.8)$ & $74(7.7)$ & $437(45.7)$ & $130(13.6)$ \\
\hline I stop taking antimalarial drugs when I feel better & $74(7.7)$ & $180(18.8)$ & $50(5.2)$ & $508(53.1)$ & $144(15.1)$ \\
\hline $\begin{array}{l}\text { I don't like taking antimalarial drugs because of the health-care } \\
\text { professionals' attitudes toward patients }\end{array}$ & $43(4.5)$ & $217(22.7)$ & $57(6.0)$ & $496(51.9)$ & $143(15.0)$ \\
\hline I forget taking antimalarial drugs because I do not have good memory & $51(5.3)$ & $267(27.9)$ & $66(6.9)$ & $442(46.2)$ & $130(13.6)$ \\
\hline $\begin{array}{l}\text { I cannot afford complete treatment for malaria due to the cost } \\
\text { involvement }\end{array}$ & $78(8.2)$ & $258(27.0)$ & $54(5.7)$ & $420(43.9)$ & $146(15.3)$ \\
\hline $\begin{array}{l}\text { I do not visit PHC facility for malaria treatment because none is near } \\
\text { my place }\end{array}$ & $62(6.5)$ & $210(22.0)$ & $52(5.4)$ & $501(52.4)$ & $131(13.7)$ \\
\hline $\begin{array}{l}\text { I do not visit health facility for malaria treatment because antimalarial } \\
\text { drugs are not always available }\end{array}$ & $55(5.8)$ & $220(23.0)$ & $49(5.1)$ & $497(52.0)$ & 135 (14.1) \\
\hline $\begin{array}{l}\text { I do not visit PHC facilities because the health-care professionals are } \\
\text { not always available }\end{array}$ & $55(5.8)$ & $130(13.6)$ & $80(8.4)$ & $547(57.2)$ & $144(15.1)$ \\
\hline
\end{tabular}

ACTs: Artemisinin-based combination therapies, PHC: Primary health care

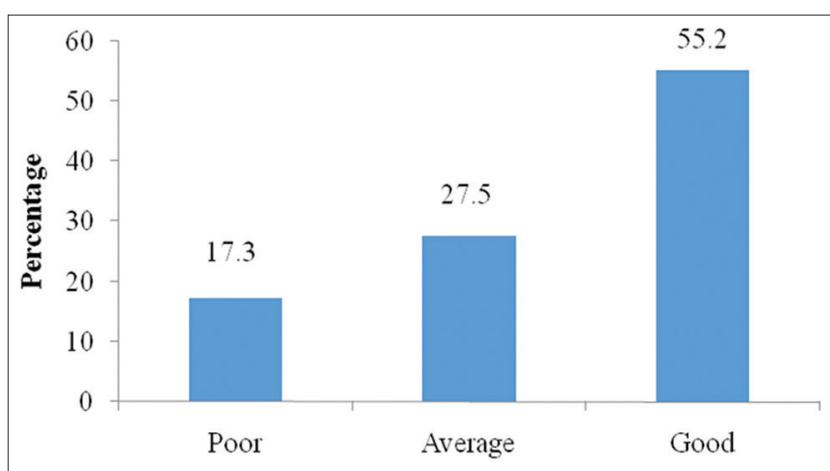

Fig. 1: Knowledge levels categorization of respondents $(n=956)$

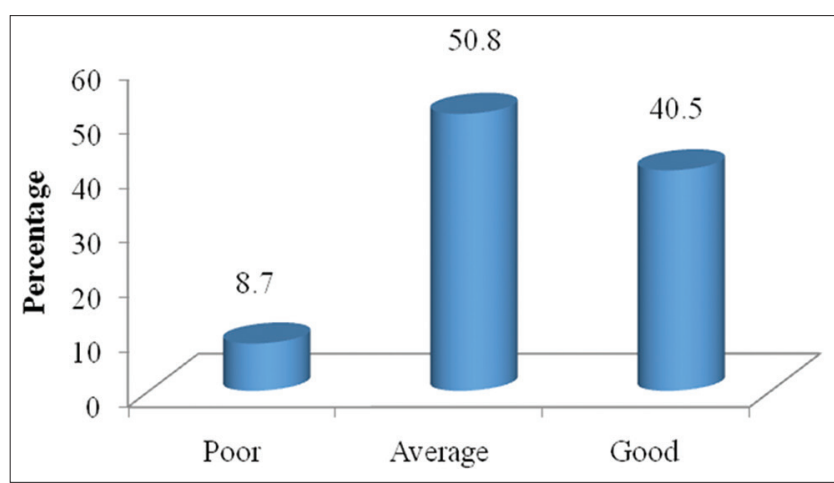

Fig. 2: Attitude levels categorization of respondents $(n=956)$ ranged between 33.8 and $57.5 \%$ and these showed respondents' general good attitudes toward the disease and its management (Table 3 ).

\section{Malaria-related attitude category}

With overall mean $( \pm \mathrm{SD})$ attitudes score of $34.55( \pm 7.20)$, majority of the respondents (50.8\%) scored between 25 and 36 points and were categorized as having average attitudes toward the disease and its management, followed by $40.5 \%$ of them who scored between 37 and 50 points that were considered having good positive attitudes toward the disease and its management. Only $8.7 \%$ of the study populations fall in the category of those that got $<25$ points and were considered as having poor attitudes (Fig. 2)

\section{Respondents' practices}

Majority of the respondents (35.6-56.2\%) reported that they often carried out their medication practices according to laid down instructions, which was followed by between 25.0 and $28.6 \%$ of the populations who responded as very often carrying out their practices in accordance to the instructions (Table 4).

\section{Malaria-related practice category}

The majority of the participants' responses $(67.1 \%)$ to all the four practice-related items were in accordance to the required laid down standards for rational medications, with overall mean $( \pm S D)$ score of 14.98 ( \pm 3.44 ) (Fig. 3). They were, therefore, categorized as performing good medication practices. Similarly, some of the respondents' medication practices were categorized as average $(23.1 \%)$ or poor $(9.8 \%)$.

\section{DISCUSSION}

Patients' KAP on uncomplicated malaria management was tested using 21-items PKAPIUM scale with Cronbach's alpha of 0.74 in PHC settings 
Table 4: Patients' practices during uncomplicated malaria management (n=956)

\begin{tabular}{llllll}
\hline Practice statements & Very often, $\mathbf{n}(\%)$ & Often, n (\%) & Sometimes, n (\%) & Rarely, n (\%) & Never, $\mathbf{n}(\%)$ \\
\hline $\begin{array}{l}\text { I take my antimalarial drugs as instructed } \\
\begin{array}{l}\text { t take my antimalarial drugs in accordance to } \\
\text { the timing interval }\end{array}\end{array}$ & $263(27.5)$ & $524(54.8)$ & $118(12.3)$ & $41(4.3)$ & $10(1.1)$ \\
$\begin{array}{l}\text { I ensure the completion of my anti-malarial } \\
\text { drugs even when I am relief of the symptoms }\end{array}$ & $244(25.5)$ & $437(56.2)$ & $125(13.1)$ & $44(4.6)$ & $11(1.2)$ \\
$\begin{array}{l}\text { I ensured diagnosis at PHC facility before taking } \\
\text { antimalarial drugs }\end{array}$ & $273(28.6)$ & $340(35.6)$ & $263(27.5)$ & $65(6.8)$ & $40(4.2)$ \\
\hline
\end{tabular}

PHC: Primary health care

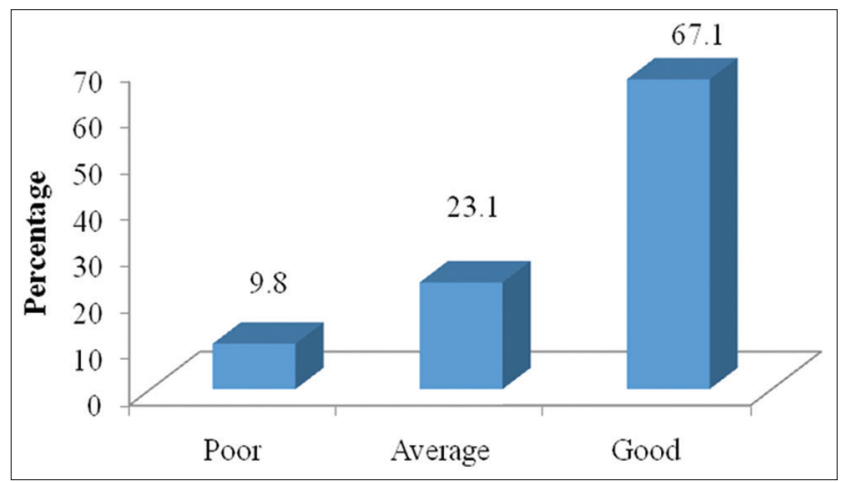

Fig. 3: Practice levels categorization of respondents $(n=956)$

of Plateau state, Nigeria. The outcome of the study indicated the majority possessed good knowledge and practices on uncomplicated malaria, with half of them having average positive attitudes toward the disease and its management.

The detailed studies on the respondents' knowledge showed that most of them $(89.0 \%)$ knew that mosquitoes bite was the main ways of transmitting malaria, and $88.5 \%$ of them also understood that children and pregnant women were at more risk of developing the disease (Table 2), which were similar to results of similar studies conducted in Colombia and Southern Nigeria, where $86.9 \%$ and $81 \%$ respondent, respectively, had good knowledge of transmission and those at risk of being affected by the disease [24,25]. These observations are also common in malaria-endemic areas where it is a known fact that children, pregnant women, HIV/AIDS patients, and malnourished [3], as well as travelers (nonimmune) from areas without malaria to malaria-endemic areas [1] are the most affected groups by the disease, which are even worst among poor populations living in rural areas without access to basic health-care facilities $[1,8]$. In some rare cases, transmission of the disease has been reported through others mean, such as from mother to fetus before or during delivery, through blood transfusion, organ transplant, or the shared use of needles or syringes contaminated with blood [26]. These results were, however, in contrasts with the report of a similar study conducted in Tanzania and Bangladesh where the level of respondents' knowledge regarding the transmission of the disease was reported to be poor [27]. Regarding signs and symptoms of the disease, most of them recognized a rise in body temperature (86.9\%) and body weakness $(84.2 \%)$ as some of the common symptoms of the uncomplicated malarial disease, which were good and consistent with results of similar studies earlier reported [25]. However, their understanding on the recommended antimalarial drug was not encouraging because only slightly above an average number of the respondents (53.2\%) could recognize artemisinin-based combination as the main drug for uncomplicated malaria. About $45.0 \%$ of the respondents were contemplating on the true position of sulfadoxine-pyrimethamine in uncomplicated malaria management, with only $22.5 \%$ of them who clearly responded that the drug was not the recommended antimalarial drug in the country, but mainly for preventive purpose, especially in pregnancy, as stated in the guideline [28]. Very good percentage of the respondents (34.6\%) still identified chloroquine as the recommended antimalarial drug for uncomplicated malaria in Nigeria, which concurred with the reported wide acceptance and perceptions of many people on the drug to be more effective in managing malaria [29]. The respondents' knowledge gaps on the drugs might be attributed to their locations and the fact that they are not trained by medical personnel [23] which could be the reason for the reported rampant use of the drugs in the country without proper recommendations from trained health-care professionals [7].

The gaps in attitudes were seen in variations of their views and beliefs based on their responses to the attitudes-related items, for instance, less than half of the population (40.8\%) disagreed or strongly disagreed with the beliefs that most of the antimalarial drugs in circulation were fake, compared to majority (59.2\%) who were on the neutral side and concurring with the issues of fake antimalarial drugs in circulation (Table 3). This might be connected with the knowledge gaps of the majority on the recommended drugs for managing the disease in the country, which might be influenced by some reported research information in circulation regarding the purported treatment failure from artemisinin-based combination therapy in western Cambodia [30,31], which is contrary to Nigeria situation, as the drug is still recognized as the most effective antimalarial drug, especially against the P. falciparum parasite responsible for over $98 \%$ of the disease in the country $[1,28]$.

The poor knowledge of the respondents on uncomplicated malaria drugs coupled with the average attitudes toward the disease and its management might be strong contributing factors to the reported high incidence of the disease in the state which comes with financial burden on the patients and society $[17,18]$, although such limitations had fewer impacts on their management practices, as majority (67.1\%) (Fig. 3) of the populations had good practices. Improving on the patients' knowledge through appropriate counseling might positively influence their attitudes toward the disease which might further improve their management practices. This is possible because a similar approach toward improving patients' awareness and prevention of dengue fever had been reported in India [32].

\section{CONCLUSION}

The overall outcome of this study indicated respondents' good knowledge and practices on uncomplicated malaria management, while their attitudes toward the disease and its management were average. The possible reasons for these gaps might be overcome through appropriate creation of public awareness as intervention measures, in addition to encouraging appropriate health-care professionals' management practices which could further help in ensuring effective use of the recommended first-line antimalarial drug for achieving optimal patients' desired therapeutic outcomes.

\section{ACKNOWLEDGMENTS}

The authors wish to appreciate all staff of primary health-care facilities in Plateau state, Nigeria, for their cooperation throughout the period of data collection. The authors also thank all patients for participating in the study despite their conditions at the time of the data collection. 


\section{AUTHORS' CONTRIBUTIONS}

Both authors participated fully in the studies. Author NSJ conceived the study idea and topic, collected, and analyzed the data. NEI supervised the study and edited the manuscript. Both authors read and approved the manuscript before submission.

\section{CONFLICTS OF INTERESTS}

The authors have declared no conflict of interest.

\section{REFERENCES}

1. World Health Organization. Guidelines for the Treatment of Malaria. Geneva: World Health Organization; 2015.

2. Fana SA, Bunza MD, Anka SA, Imam AU, Nataala SU. Prevalence and risk factors associated with malaria infection among pregnant women in a semi-urban community of North-Western Nigeria. Infect Dis Poverty 2015;4:24

3. Burlando A, Chukwuocha UM, Dozie IN, Crompton PD, Moebius J, Waisberg $\mathrm{M}$, et al. Malnutrition: The leading cause of immune deficiency diseases worldwide. Internat J Afr Nurs Sci 2014;3:4327-38.

4. Ahmad A, Mast MR, Nijpels G, Elders PJ, Dekker JM, Hugtenburg JG, et al. Identification of drug-related problems of elderly patients discharged from hospital. Patient Prefer Adherence 2014;8:155-65.

5. Bennadi D. Self-medication: A current challenge. J Basic Clin Pharm 2013;5:19-23

6. Edet-Utan O, Ojediran T, Usman S, Akintayo-Usman NO, Fadero T, Oluberu OA, et al. Knowledge, perception and practice of malaria management among non-medical students of higher institutions in Osun State Nigeria. Am J Biotech Med Res 2016;1:5-9.

7. Ezenduka CC, Ogbonna BO, Obinna EI, Mathew JO, Esimone CO. Antimalarial drugs use pattern in retail outlets in Enugu urban SouthEast Nigeria: Implication for malaria treatment policy. Malar J 2014;13:243.

8. Lutala PM, Kasereka CM, Kasagila EK, Inipavudu JB, Toranke SI. Quality assurance of malaria case management in an urban and in subrural health centres in Goma, Congo. Afr J Prim Health Care Fam Med 2011;3:8.

9. Noland GS, Graves PM, Sallau A, Eigege A, Emukah E, Patterson AE, et al. Malaria prevalence, anemia and baseline intervention coverage prior to mass net distributions in abia and plateau states, Nigeria. BMC Infect Dis 2014;14:168.

10. Haynes RB, Ackloo E, Sahota N, McDonald HP, Yao X. Interventions for enhancing medication adherence. Cochrane Database Syst Rev 2008;2:CD000011

11. Brown MT, Bussell JK. Medication adherence: WHO cares? Mayo Clin Proc 2011;86:304-14.

12. Yadav SP, Yadav S, Kuma P, Yadav S. Knowledge, treatment-seeking behaviour and socio-economic impact of malaria in the desert of Rajasthan, India. South Afr J Epidemiol Infect 2013;28:41-7.

13. Jimmy B, Jose J. Patient medication adherence: Measures in daily practice. Oman Med J 2011;26:155-9.

14. Ahmad A, Munn Sann L, Abdul Rahman H. Factors associated with knowledge, attitude and practice related to hepatitis B and C among international students of universiti putra Malaysia. BMC Public Health 2016;16:611.

15. Wahed T, Kaukab SS, Saha NC, Khan IA, Khanam F, Chowdhury F, et al. Knowledge of, attitudes toward, and preventive practices relating to cholera and oral cholera vaccine among urban high-risk groups: Findings of a cross-sectional study in Dhaka, Bangladesh. BMC Public
Health 2013;13:242.

16. Zawahir S, Hettiarachchi C, Morrissey H. Assessing knowledge, perception and attitudes about antibiotics among final year pharmacy undergraduates in Sri Lanka. Int J Pharm Pharm Sci 2017;9:234-9.

17. Eke RA, Diwe KC, Chineke HN, Duru CB, Uwakwe KA. Evaluation of the practice of self-medication among undergraduates of imo state university (IMSU) Owerri, South-East Nigeria. Orient J Med 2014;26:79-83.

18. Liu J, Isiguzo C, Sieverding M. Differences in malaria care seeking and dispensing outcomes for adults and children attending drug vendors in Nasarawa, Nigeria. Trop Med Int Health 2015;20:1081-92.

19. National Population Commission (NPC) [Nigeria], National Malaria Control Programme (NMCP) [Nigeria], and ICF International. (2012). Nigeria Malaria Indicator Survey 2010. Available from: http://www. dhsprogram.com/what-we-do/survey/survey-display-392.cfm. [Last accessed on 2018 Apr 16].

20. Elmannan AA, Elmardi KA, Idris YA, Spector JM, Ali NA, Malik EM, et al. Anti-malarial prescribing practices in sudan eight years after introduction of artemisinin-based combination therapies and implications for development of drug resistance. BMC Pharmacol Toxicol 2015;16:3.

21. World Health Organization. How to Investigate Drug Use in Health Facilities, Geneva: World Health Organization; 1993. Available from: http://www.apps.who.int/medicinedocs/pdf/s2289e/s2289e.pdf. [Last accessed on 2017 Dec 24]

22. Fuge TG, Ayanto SY, Gurmamo FL. Assessment of knowledge, attitude and practice about malaria and ITNs utilization among pregnant women in Shashogo district, Southern Ethiopia. Malar J 2015;14:235.

23. Jimam NS, David S, Musa N, Kadir GA. Assessment of the knowledge and patterns of malaria management among the residents of jos metropolies. World J Pharm Pharm Sci 2015;4:1686-98

24. Forero DA, Chaparro PE, Vallejo AF, Benavides Y, Gutiérrez JB, Arévalo-Herrera M, et al. Knowledge, attitudes and practices of malaria in Colombia. Malar J 2014;13:165.

25. Adetola OT, Aishat LL, Olusola O. Perception and treatment practices of malaria among tertiary institution students in Oyo and Osun states, Nigeria. J Nat Sci Res 2014;4:30-3

26. Okoli CA, Okolo SN, Collins JC. Plasmodium falciparum infection among neonates in the north central region of Nigeria. J Infect Dev Ctries 2013;7:365-71.

27. Ahmed SM, Haque R, Haque U, Hossain A. Knowledge on the transmission, prevention and treatment of malaria among two endemic populations of Bangladesh and their health-seeking behaviour. Malar J 2009;8:173.

28. Federal Ministry of Health (FMOH). National Guidelines for Diagnosis and Treatment of Malaria. $3^{\text {rd }}$ ed. Abuja: Federal Ministry of Health; 2015.

29. Zucker JR, Ruebush TK $2^{\text {nd }}$, Obonyo C, Otieno J, Campbell CC. The mortality consequences of the continued use of chloroquine in Africa: Experience in Siaya, Western Kenya. Am J Trop Med Hyg 2003;68:386-90

30. Noedl H, Se Y, Schaecher K, Smith BL, Socheat D, Fukuda MM, et al. Evidence of artemisinin-resistant malaria in Western Cambodia. N Engl J Med 2008;359:2619-20.

31. Dondorp AM, Nosten F, Yi P, Das D, Phyo AP, Tarning J, et al. Artemisinin resistance in Plasmodium falciparum malaria. N Engl $\mathbf{J}$ Med 2009;361:455-67.

32. Sabishruthi S, Vedha-Pal-Jeyamani S, Kavitha S, Ponsegaran V, Magesh M. Assessing and empowering counselling a patient with severe dengue fever associated with thrombocytopenia. Int J Pharm Pharm Sci 2018; 10:147-50. 